\title{
Outcomes of Laparoscopic Pyloromyotomy with Microscope and Stab Incision vs. Open Pyloromyotomy in Infantile Hypertrophic Pyloric Stenosis; Single Institution Experience
}

Yoon Jung Boo, M.D, Ph.D.

Division of Pediatric Surgery, Department of Surgery, Korea University College of Medicine, Seoul, Korea

Corresponding author

Yoon Jung Boo

Division of Pediatric Surgery, Department of Surgery, Korea University College of Medicine, 73 Inchon-ro Sunngbuk-gu, Seoul 02841, Korea

Tel: +82-2-928-1631, Fax: +82-2-920-6844, E-mail: drboo@korea.ac.kr

See the article Outcomes of Laparoscopic Pyloromyotomy with Microscope and Stab Incision vs. Open Pyloromyotomy in Infantile Hypertrophic Pyloric Stenosis; Single Institution Experience. J Min Invasive Surg. 2016 March; 19(1);9.

This is an Open Access article distributed under the terms of the Creative Commons Attribution Non-Commercial License (http:// creativecommons.org/licenses/by-nc/4.0/) which permits unrestricted non-commercial use, distribution, and reproduction in any medium, provided the original work is properly cited.
Copyright @ 2016 The Journal of Minimally Invasive Surgery. All rights reserved.
한림대학교 성심병원의 안수민 교수가 기고한 “Outcomes of laparoscopic pyloromyotomy with microscopic and stab incision vs. open pyloromyotomy in infantile hypertrophic pyloric stenosis; Single center experience"는 유문협착증의 복강경 수술 과 기존의 개복수술의 결과를 비교한 논문입니다.

유문협착증의 복강경 수술은 소아 복강경 수술 중 유효성에 대한 검증이 가장 잘 이루어진 수술 중 하나로 많은 연구자들 에 의해 시행된 무작위 비교 논문에서 안정성이 검증되었고 기 존의 수술에 비해 합병증이 임상적으로 유의하게 증가하지 않 으면서 좀 더 빠른 회복을 가져오는 것으로 밝혀졌습니다. ${ }^{2-4}$ 따 라서 최근의 가이드라인은 경험 많은 소아외과 전문의가 있는 병원에서는 유문협착증의 우선적 수술적 치료 방법으로 추천되 고 있습니다. ${ }^{5}$ 그러나 해외에서는 이미 많은 연구가 시행되어 추 천되고 있는 수술법임에도 불구하고 우리나라에서는 아직 잘 디자인된 연구가 보고되지 않았다는 점에서 본 연구가 의미가 있다고 할 수 있습니다.

본 연구에서는 기존의 개복 수술에 비해 복강경 수술이 합 병증이나 수술시간 등에 차이가 없으면서도 빠른 회복과 짧은
재원기간을 보여주었습니다. 또한 복강경 수술이 수술 흥터의 만족도에서도 유의하게 높은 점수를 나타내었습니다. 그러나 저 자들이 기술한 microscope사용이나 stab incision 등의 술기는 기존의 복강경유문근절개술에 이미 널리 사용되었던 방법으로 새로운 복강경 기술이라 하기에는 무리가 있습니다. 또한 고찰 에서 저자들이 기술한 stab incision 기술을 기존의 복강경 트 로카 삽입법과 비교하는 추후연구에 대한 필요성은 한번 더 재 고해 보는 것이 좋겠습니다. 소아, 특히 복강내 공간이 좁은 영 아의 복강경 수술에서는 stab incision이 복강경 기구 및 트로 카 삽입시 손상을 방지하기 위해 널리 사용되는 방법입니다. 향 후 복강경 유문근절개술에 대한 연구를 더 진행한다면 오히려 최근 논란이 되고 있는 불완전 유문근 절개의 가능성이나 경험 이 많지 않은 술자에 의해 복강경 수술이 시행될 경우 천공 등 의 합병증 발생 가능성에 대해 술자의 학습곡선과 함께 비교, 분석하는 것이 더 바람직한 방향이 될 것으로 생각됩니다. ${ }^{6,7}$

흥터에 대한 만족도 조사는 수술 후 언제 시행되었는지가 중 요합니다. 수술 후 흥터는 지속적으로 리모델링되고 소아의 경 우는 특히 더 많은 변화가 있으므로 수술 직후의 만족도와 수 
술후 수개월 후의 만족도는 차이가 있을 수 있습니다. 특히 최 근의 유문근절개술은 개복하더라도 배꼽주위 절개가 더 선호 되므로 본 연구에서 사용하는 우상복부 절개술에 비해 수술 후 흥터가 더 만족스러운 경우가 많습니다.

흔하지 않는 영아의 질환에 대해 복강경 수술의 유효성에 대 해 연구를 진행하고 회원들에게 유익한 정보를 제공해 주신것 에 대해 저자들께 감사드립니다.

\section{REFERENCES}

1) Kim TA, Sung TY, Kang WM, Ahn SM. Outcomes of laparoscopic pyloromyotomy with microscope and stab incision vs. open pyloromyotomy in infantile hypertrophic pyloric stenosis; single institution experience. J Minim Invasive Surg 2016. (in press).

2) St Peter SD, Holcomb GW, 3rd, Calkins CM, et al. Open versus laparoscopic pyloromyotomy for pyloric stenosis: a prospective, randomized trial. Ann Surg 2006;244:363-370.

3) Hall NJ, Pacilli M, Eaton S, et al. Recovery after open versus laparoscopic pyloromyotomy for pyloric stenosis: a double-blind multicentre randomised controlled trial. Lancet 2009;373:390-398.

4) Leclair MD, Plattner V, Mirallie E, et al. Laparoscopic pyloromyotomy for hypertrophic pyloric stenosis: a prospective, randomized controlled trial. J Pediatr Surg 2007;42:692-698.

5) Oomen MW, Hoekstra LT, Bakx R, Ubbink DT, Heij HA. Open versus laparoscopic pyloromyotomy for hypertrophic pyloric stenosis: a systematic review and meta-analysis focusing on major complications. Surg Endosc 2012;26:2104-2110.

6) Hall NJ, Eaton S, Seims A, et al. Risk of incomplete pyloromyotomy and mucosal perforation in open and laparoscopic pyloromyotomy. J Pediatr Surg 2014;49:1083-1086.

7) Sattarova V, Eaton S, Hall NJ, Lapidus-Krol E, Zani A, Pierro A. Laparoscopy in pediatric surgery: Implementation in Canada and supporting evidence. J Pediatr Surg 2016. (in press). 